\title{
VIGITEL Brasil 2013: Vigilância de Fatores de Risco e Proteção para Doenças Crônicas por Inquérito Telefônico
} Vigitel Brazil 2013: Protective and Risk Factors for Chronic Diseases by Telephone Survey

Vigitel Brasil 2013: Vigilancia de Elementos de Riesgo y Protección para las Enfermedades Crónicas por Cuestionamiento Telefónico

\author{
Ministério da Saúde (Brasil). \\ Brasília, DF: Ministério da Saúde, 2014. 120p.
}

Taís Facina ${ }^{1}$

Esta publicação apresenta os dados do oitavo ano (2013) de operação do programa Vigilância de Fatores de Risco e Proteção para Doenças Crônicas por Inquérito Telefônico, o Vigitel. São informações de todas as capitais dos Estados brasileiros e do Distrito Federal sobre frequência, distribuição e evolução dos principais fatores que determinam as doenças crônicas no país.

Implantado em 2006, é uma iniciativa do Ministério da Saúde, com suporte técnico do Núcleo de Pesquisas Epidemiológicas em Nutrição e Saúde da Universidade de São Paulo (NUPENS/USP), que tem por objetivo monitorar, por inquérito telefônico, os principais determinantes das Doenças Crônicas Não Transmissíveis (DCNT), fazendo parte do sistema de vigilância das DCNT do Ministério e contribuindo na formulação de políticas públicas que promovam a melhoria da qualidade de vida da população brasileira. Os resultados desse sistema embasaram, por exemplo, a elaboração do Plano de Ações Estratégicas para o Enfrentamento das Doenças Crônicas no Brasil 2011 2012 e serviram de subsídio para o monitoramento das metas propostas no plano nacional e no Plano de Ação Global para a Prevenção e o Controle das DCNT, da Organização Mundial da Saúde (OMS).

Segundo o livro, as DCNT correspondem a 72,4\% das causas de morte no Brasil, tendo aumentado em mais de três vezes entre 1930 e 2006. Essas mortes por DCNT são causadas, na maioria das vezes, por um pequeno conjunto de fatores de risco e por fração substancial da carga de doenças em razão dessas enfermidades. Entre esses fatores, destacam-se o tabagismo, o consumo excessivo de bebidas alcoólicas, dietas inadequadas e a inatividade física.

Foram aproximadamente 53 mil entrevistas. As estimativas de indicadores de 2013 foram em relação ao tabagismo, à prevençáo do câncer, ao excesso de peso e à obesidade, ao consumo alimentar, à atividade física, ao consumo de bebidas alcoólicas, à condução de veículo motorizado após consumo de qualquer quantidade de bebida alcoólica, à autoavaliação do estado de saúde e à morbidade referida.

Nos itens citados acima, entre os fatores de risco, foram incluídos hábito de fumar, excesso de peso, consumo de refrigerantes, doces e alimentos fontes de gordura saturada, inatividade física e consumo de bebidas alcoólicas, além da referência ao diagnóstico médico de hipertensão arterial, diabetes e dislipidemias.

Entre os fatores de proteção, foram incluídos a prática de atividade física no tempo livre e no deslocamento para o trabalho, curso ou escola, o consumo de frutas e hortaliças e de feijão, e a realização de exames para detecção precoce de tipos comuns de câncer em mulheres (mamografia e citologia oncótica para câncer de colo do útero).

Um dos dados apresentados no livro é em relação à detecção precoce e prevenção do câncer. No que diz respeito às mulheres (de 50 a 69 anos) que realizaram o exame de mamografia nos últimos dois anos, o inquérito mostrou que houve um aumento significativo, passando de 71,1\% em 2007 para 78\% em 2013. As maiores frequências de mulheres entre 50 e 69 anos de idade, que referiram ter realizado exame de mamografia nos últimos dois anos, foram

1Jornalista, pós-graduada em "Produção do Livro", editora de publicaçōes científicas no Instituto Nacional de Câncer José Alencar Gomes da Silva (INCA). 
observadas em Salvador (86,4\%), Vitória (86,3\%) e Florianópolis $(85,7 \%)$ e as menores em Rio Branco (64,7\%), Belém (66,5\%) e Macapá $(66,8 \%)$.

Em relaçáo ao tabagismo, um fator de risco para o desenvolvimento de uma série de DCNT, como câncer, doenças pulmonares e doenças cardiovasculares, o Vigitel produz estimativas de vários indicadores do hábito de fumar entre adultos e leva em consideração a frequência, intensidade e idade do início do hábito de fumar. Foram observadas redução progressiva do tabagismo, redução progressiva da prevalência de fumantes pesados (20 cigarros por dia) e redução de fumantes passivos no domicílio.

Outros resultados apresentados pelo Vigitel foram:

- A estabilizaçáo, pela primeira vez, entre 2012 e 2013, da tendência de crescimento contínuo de excesso de peso e obesidade.

- O aumento no consumo recomendado ( $\geq 5$ porções diárias) e regular ( $\geq 5$ dias por semana) de frutas e hortaliças.

- O aumento da prática de atividade física no lazer.

- O crescimento do número de homens e mulheres que se autorreferem com diabetes. 